\title{
International Partnership of the University as a Factor of Competitiveness in the Framework of the Formation of Professional Competencies
}

\section{Maria Olegovna Suraeva ${ }^{1}$}

E. P. Fomin

\section{G.P. Gagarinskaia}

${ }^{1}$ Samara State University of Economics; Russian Federation, Samara; Correspondence: Maria Suraeva 443090, Samara, st. Sovetskoy Armii 141, Russian Federation, Samara, Email: panda63d@mail.ru

\section{Doi:10.5901/mjss.2015.v6n6s3p416}

\section{Abstract}

\begin{abstract}
Among the main problems of operation that the Russian higher education system comes across in conditions of the global economy at the contemporary stage of social and economic development of the country a separate place is taken by ensuring high competitive ability of higher educational institutions in general and separate educational programs in particular. In this context competitive ability may be reviewed not only as a possibility of the higher educational institution to obtain significant advantages before other higher educational institutions of the educational market that offer educational services similar in content and volume but also a possibility to produce high quality specialists with a set of competences complying with the requirements and expectations of the Russian and international labour markets. The article offers a method for evaluation of competitive ability of a higher educational institution based on the integral index showing quantitative parameters of international cooperation established by the higher educational institution itself and qualitative characteristics defined by the higher educational institution service consumers that will allow classifying the international partnership evaluation parameters and specifying the evaluation carrying out process.
\end{abstract}

Keywords: higher educational institution, higher education, international partnership, innovations, professional competence forming.

\section{Introduction}

Competitive ability triggers the necessity to look for new and relevant approaches to development and implementation of the higher educational institution development strategies in the international partnership area, research and classification of the main forms and possibilities of adaptation of the world achievements in the higher education sphere that may cause a significant impact on the quality of services provided by the higher educational institutions.

It is important to note that today the quality of education provided by some higher educational institutions seriously lags behind as compared to the education provided by the leading US and European universities. That is the reason why many foreign companies do not acknowledge higher education diplomas issued by Russian higher educational institutions.

Objective evaluation of competitive ability of a higher educational institution is fundamental for the solution a task of ensuring management efficiency of a higher educational institution as the main participant of the higher professional education system. Moreover, the contemporary situation requires not only objective and comprehensive evaluation of the current competitive ability of a higher educational institution but also high quality forecast of its future development by revelation of the key factors of efficient management of a higher educational institution and the factors ensuring its innovative development.

\section{International Educational Environment - Unified System of Cooperation between National Education Systems}

A characteristic trait of international development in the last decade of the previous century is integration processes in the sphere of economy that in their turn initiate similar processes in other areas: education, science, technology, etc. Western Europe is leading the way in this respect pursued by Latin America and Asia Pacific Region.

The number of higher educational institutions including private ones grows significantly; along with the classical 
universities new ones are being established that offer their services to a broad audience of consumers paying little attention to the education quality.

The possibilities for relocation of students from one country to another have grown immensely. The increased mobility helps fully satisfy the demands of a person to receive the education the national system is unable to provide. About one million students worldwide are currently studying outside their countries. Their share is growing every year constituting a significant part of the educational service market.

To characterize the situation in the world education in general one should pay attention to the tendency of strengthening of cooperation between the educational institutions and education systems of various countries creating the world educational service market.

An intense money flow redistribution process takes place in this educational environment. A large part of the money flows has already been captured by large providers applying modern education technologies that we are coming to with significant delay. The funds accumulated by the world educational service market are huge. Students pay billions of dollars on an annual basis.

However, following the well-known crisis events we find ourselves in a situation of possible loss of independence on the educational service market including from the point of securing of our geopolitical interests. Some people are under a delusive impression that there are no difficulties in implementation of international cooperation.

As a result, the international cooperation undergoes an imperceptible process of being broken down by separate forms of activity, separate subdivisions and structures and even separate performers. Possibilities of coordinated actions by priority lines (retraining and requalification, various forms of additional education, some forms of scientific and technical cooperation) that can ensure effect have noticeably dropped.

From the start of the 80-s the universities of Great Britain have stirred to activity. The underlying cause of such activity was the decision of the government resulting in transfer of education of the foreign citizens in the universities to a fee-paying basis.

In our opinion the joint efforts of the international educational service market may serve to: review the demand for the educational services in the countries (regions), carry out advertising and information campaigns, protect legal rights and interests of the universities in state authorities (in own country and abroad), establish foreign representative offices, issue joint specialized publications, organize exhibitions and much more.

The higher education system is managed by the corresponding ministry or agency on the national level and local authorities on the regional level.

In Canada, for instance, the operation of higher educational institutions on the national level is coordinated by the Council of Ministers of Education responsible for education plans and programs, education means, development of official language programs, participation in international conferences and exchanges in the education sphere.

In Germany the higher education system on the state level is managed by the Federal Ministry of Education and Science, in Great Britain - by the Department of Education and Science. There is no direct control over the activity of the educational institutions on their part although their impact has lately significantly increased.

The peculiarity of the system of higher education management in Japan lies in the fact that the management level depends on the higher educational institution category (state, municipal or private). State universities are under control of the Ministry of Education, Science and Culture, municipal ones are controlled by the local public authorities, private - by the individuals having the corresponding legal rights (Lorange P., 2002).

Thus, one may note an important detail characteristic of the education system in the developed countries: the national government of the developed countries only defines the general policy in the education sphere, coordinates the activity of education ministers and agencies of states and local education authorities, establishes the requirements and criteria higher educational institutions and diplomas of higher education should comply with, distributes the federal budget and executes control over its implementation, provides information on the possibilities of the higher educational institution. No higher educational institutions are under control of the federal government.

In the federative countries the ultimate management of the higher educational institutions is implemented on the regional and local levels (for example, ministries of lands in Germany responsible for higher education, departments of education (or ministries of education in some provinces) in Canada, departments of education or local authorities in the USA).

In the countries with a traditionally strong centre (France) the decision making right on a large number of issues concerning higher education earlier being the exclusive right of the government is also transferred to the regional and local management authorities. As a rule, the management form of university in the developed countries consists of two levels: academic council (senate) in Great Britain; local university self-government body headed by the university president and a board of governors (trustees) in the USA and Canada; kuratorium in Germany (Annuaire statistique de la 
France, 1999; Education in a Federal System, 1995; Federal Republic of Germany, 1996).

One may note the following peculiarities of the education management system in the USA:

- Higher educational institutions in the USA are under no control of the federal authorities (apart from some specialized institutions);

- Public colleges and universities are governed by the states or local authorities that provide the main financial assistance;

- Independent colleges and universities (private) are governed by their own independent councils (Mestenhauser Josef A., Ellingboe B.J., 1998).

The activity of the universities in Great Britain is governed by their royal charters or constitutions. Such charters were approved by a privy council or parliament in the course of decision making on establishment of a university (Clark B. R.. 1998).

The universities of Great Britain compared to the universities of other countries have an exclusive degree of autonomy and management freedom. In particular, they have a right of employment; a right to admit students although there exist some limitations in the number and proportions of students depending on the study sphere (humanities, science, medicine), develop education programs and performance control methods; carry out their own research programs; solve funds distribution issues.

In China educational institutions have lately received more independence in decision making:

- Some higher educational institutions have been granted with rights to admit students in excess of the quota set by the state admission plan;

- Administration of higher educational institutions has a right to select and appoint professors;

- Higher educational institutions receive more independence in funds distribution;

- Some higher educational institutions get more rights to distribute capital investments;

- Higher educational institutions are provided with possibilities to help employment of their graduates and establish direct contact with the institutions and enterprises interested in the graduates of such higher educational institutions.

It should be noted that foreign higher educational institutions had to sustain severe pressure from the state structures at transfer to the specific self-government schemes before consensus was reached. It has now been generally accepted that in the contemporary conditions strict centralized management of higher educational institutions by the government is inefficient. A specific approach to the distribution of powers and extension of rights of the educational institutions is required for successful development of higher education.

Thus, foreign experience of the higher education system management has a number of drawbacks and advantages and its analysis could impact reforming of the education system.

Another important aspect in operation of the education system in the last ten years is an issue of introduction of multi-level higher education. Developed foreign countries have accumulated vast experience in the implementation of advantages of breaking the education system into complementary and interdependent blocks.

Foreign universities and colleges award academic or professional degrees or titles to the graduates of higher educational institutions. Academic degrees are an official confirmation of successful completion of a specific education course. English-speaking countries traditionally have three levels of higher education that are completed by awarding a degree of Bachelor (of Arts, Science), Master (of Arts, Science), Ph.D. accordingly.

The Bachelor degree is the most frequent in the foreign higher educational institutions. The students continuing education usually follow a sequential scheme Master - Doctor. However, in a number of cases this procedure may not be followed. In some countries the Master degree is not an obligatory condition for admission to the doctoral program, and the Bachelor degree is not required for post-graduate studies. Honorary degrees are awarded irrespective of the presence of the academic degrees.

Up to the present day the Bachelor degree is the main degree in Great Britain, countries of the Commonwealth and the USA. No less than 3-4 years are required to receive a Bachelor degree. Study in the Middle East countries where the Bachelor degree is likewise the first step takes up 3-5 years (Saudi Arabia, Syria, Kuwait, Libya). In Japan the Bachelor degree is given after 4 years.

In many countries of continental Europe and Latin America Bachelor is not the first academic degree. In France, a number of former colonies, Spain and many countries of Latin America the secondary school graduates receive the Bachelor degree. It gives a right to apply to the universities. Traditionally the first university degree in France has been the degree of Licentiate. It is an obligatory condition for admission to the examination for the professional aptitude certificate in secondary education that gives a right to occupy vacant professor positions. 
In Italy there is only one academic degree - Doctor. It is also the first degree. The duration of study in this case is 4-6 years. State examinations have to be passed to receive a right to practical activity (Visalberghi A., 1995).

The most wide-spread second academic degree in the English-speaking countries is Master. In the universities of Oxford and Cambridge the degree of Master of Arts can be received after a five-year period of graduation from the university based on the published works and paid cash contribution. Integration of the master and doctoral programs in a number of cases is characteristic of Great Britain. It should be noted that the Master degree as well as the Bachelor degree receives many options. Apart from the Master of Arts or Science there now exists a Master of Business Administration, Education, Forestry, Machine Building, etc.

The clearest implementation of the Bachelor-Master-Ph.D. scheme is in the USA and Japan. Only the Master degree holders can get admitted to a doctoral program. The minimum term of study is 3 years. In Great Britain Ph.D. can be received without a Master degree.

As practice shows, a three-step specialist training system Bachelor-Master-Ph.D. corresponds to the market economy to the largest extent. Quick and sometimes unpredictable change of the labour market environment does not let higher educational institutions react to its demands adequately and in full.

However, a three-step (or three-level) specialist training system does not dominate abroad.

There are many other options with various forms of the higher education levels. The example of the Western European countries is indicative as each of these countries has its own higher education system that has in many aspects preserved its national traditions and implements foreign experience only after its thorough analysis in relation to specific social and economic conditions.

Common educational environment of CIS means a part of geographical environment of the former USSR where the activity of educational, scientific, cultural and information institutions is coordinated on the basis of the voluntary accepted liabilities, historical community of people living on this territory and is aimed at achievement of approved objectives and fulfillment of the general historical purpose (A.I. Baranovsky, 2005; E.N. Malygina, 2008; N.Sh. Nikitina, 2003).

The concept of common education space in CIS should be built on the basis of the international cooperation principles, recognition of the right of each country to its development model, respect to the cultural identity of each nation.

The following main drawbacks of the traditional education model may be singled out following its analysis:

1) Intense and ideology-based pedagogic function of education;

2) Unification of the volume and level of received knowledge;

3) Large number of professional education areas and specializations;

4) State education monopoly.

On the other hand, the obvious advantages of the Soviet education system were: general and free secondary education; high status of the teaching profession carefully maintained by the government; elaborate methodical basis of the subjects, courses and disciplines; well-developed system of pre-school and extra-curriculum upbringing and education; provision of textbooks, additional materials and equipment for the process of study; sophisticated system of student motivation to receive high grades.

It is expedient to review positive experience of higher education in some western countries to eliminate the existing drawbacks preserving positive achievements of the old Soviet higher education system.

It is obvious enough that integration of Russia in the world community is impossible without integration of the educational system since only convertibility of education ensures equal cooperation in all areas of international politics and economy.

The emerging term "Eurasian educational standard" reflects the tendency that was long ago outlined in the CIS countries. Four countries (Russia, Belarus, Kazakhstan and Kyrgyzstan) have already made the first steps aimed at integration including but not limited to the sphere of education. On condition of development of the corresponding efficient mechanism the Eurasian countries may be the first ones to implement practical measures on mutual acknowledgement of diplomas, certificates and qualifications (A.N. Gvozdenko, 2006; A. Livandovskaya, 2006; materials of the Vth All-Russian Research and Practical Conference, 2006).

Transfer to the market economy, refusal from command-administrative management methods, desire to get integrated in the world economic and educational community sets earlier unknown objectives before the higher educational system.

Thus, one can make the following conclusions on the similar tendencies in the educational system development and updating:

- The role and value of education is gradually growing in the society, the authority of intellectual development is established; 
- Mass professional development of young people, their desire to get elite education is obvious;

- Education is becoming more fundamental, develops professional thinking and skills;

- Student training is built with an account of diversified cultural development including but not limited to historical, environmental and esthetic character;

- Continuous education and upbringing system that transfers to lifelong learning is gradually forming;

- Educational systems have started to combine traditional and alternative education, the role of private education has increased.

Considering the development and forming of the Russian educational system one may note that the current national model is a result of reforms of systemic character (E. Sadovaya, L. Andrukovich, 2009; M.G. Sergeeva, 2007; I.I. Topilina, 2011). The established national educational model has preserved the fundamental and scientific character and implemented peculiarities of the western models - educational grants; however, some elements of the western experience - multilevel specialist performance assessment system, test forms of knowledge control, credit educational system, etc. have not presently become an efficient means of higher education quality increase as they have been borrowed superficially.

In general the educational reforms have corresponded to the main human development principles. However, the problems of higher education development efficiency increase still remain important and relevant.

Analysis of the higher education system management has shown that in the beginning of the XXI century there is a tendency of increase of autonomy of higher educational institutions concentrated on the following trends:

- Increase of social responsibility of higher educational institution before the society and regions;

- Legislative division of functions and responsibility between various higher education management levels;

- Increase of control over higher educational institutions by education service consumers (students, parents, corporate customers, business structures, etc.);

- Shift of the higher educational institution focus to the quality of provided educational services with an account of consumers' interests;

- Diversification of financing sources, financing system is used as education stimulation and management mechanism;

- Attraction of public organizations to the management and control over the higher educational institutions (boards of trustees of higher educational institutions, international accreditation of higher educational institutions, etc.).

Historical experience of establishing the Russian higher education and analysis of the main development tendencies of foreign higher education (Management of Higher Educational Institution, 2009; M.A. Cheshkov, 1998) proves that combination of ideas and knowledge of different civilizations gives birth to innovative knowledge being a driving force for the human society development. The current Russian higher education system should produce specialists with perfect understanding of the realities of their own country and political, economic and cultural life abroad (Aigner H., 1995; Coolahan J., 1995; Developpement de l' education, 1996). From the professional point of view they have to acquit themselves well in international cooperation and international competition. In order to achieve that, higher educational institutions should combine their efforts to preserve, strengthen and develop the best national traditions, master progressive trends of the world higher education and solve the problems of the world community collectively.

\section{Methods and Criteria for Assessment of Higher Education Performance Efficiency}

Contribution of education to the national income increase may be assessed by multiplication of educational fund growth by "human investment" return rate.

This method was used by E. Denison (D. Shevchenko, 2003) whose research of the economic growth sources is widely known. Similar efforts to assess contribution of education were made by T. Shults (L. Grebnev, 2004). However, notwithstanding different calculation techniques one may reveal methodological similarity of both researches as their main focus is the income differences of people with different educational levels. Practical application of both methods has been confirmed by the calculated results.

In order to assess the value of contribution of higher education to the economic growth using this method one should multiply the growth of workforce with higher education diplomas by the difference (in base year) between the incomes of people with higher and secondary education.

In order to reveal the essence of the ratio of education contribution to economic growth it may be useful to get it compared with the internal return rate. 
So the contribution weight may be explained both by high efficiency at small cost increase and by low efficiency at high cost increase.

This ability to make correct decisions has been named distributive efficiency. Distributive effect stipulates that the higher the education level the greater the tendency to innovation.

S. Deresh (L. Grebnev, 2004) noted that importance of education as an economic growth source is not as high as commonly considered.

One of his main arguments is that education is not the ultimate cause of growth rather its indispensable prerequisite.

Other authors believe that most of S. Deresh's ideas are non-constructive and note that education is a source of potential economic growth.

Thus in the last 50-60 years the economists have undoubtedly advanced in the education efficiency research.

One may come across serious shortcomings in some theoretical conclusions in respect of the efficiency problem under consideration. It is explained by a number of difficulties at economic research of non-production areas not encountered at material production examination.

As a result, the link between investments of material and human resources used in non-production sphere and the economic effect is not always obvious and straightforward.

The given theoretical research has revealed presence of various views and concepts on the education efficiency problem.

Irrespective of these differences one cannot help noting that possession of a large stock of knowledge and better educational basis undoubtedly renders significant economic effect for the person and the state and society in general.

Higher education requires special criteria of correspondence of its costs and results to the society demands since education as a non-production sphere satisfies social demands of a person and the society in general as a unified social organism.

In the process of the educational service research it is important to review each criterion as a part of the whole, trace interconnection of elements and interrelation.

One may single out several education efficiency components that in conjunction characterize general education efficiency: personality, region, state, employers, higher educational institution.

Thus, exterior system criterial levels represent macroeconomic efficiency of educational services, internal criteria represent microeconomic efficiency. Final efficiency of all criteria is revealed at the labour market.

There exist two concepts on the problem of economic efficiency measurement:

- Efficiency measurement based on one ratio,

- Or based on a system of ratios.

The main point of the unified efficiency ratio supporters (S.G. Strumilin, V.A. Trapeznikov, etc.) is the idea that notwithstanding its complexity and multitude economic efficiency represents a single objective and allows establishing the general primary ways to reaching this objective (I.I. Topilina, 2011). So they make a conclusion that the achieved results and costs of any economy level may be assessed and analyzed from the unified positions.

Supporters of this approach believe that the only difficulty of the efficiency category is that it is formed based on the economy levels. It should be noted that this concept is absolutely outdated.

The second approach (T.S. Khachaturov, P.Y. Oktyabrsky, etc.) has appeared under the influence of the system analysis concepts and development of the statistical ratio theory (S.A. Mokhnachev, 2008). It is acknowledged as the most correct one as it allows taking into account hierarchical structure of the efficiency category, multitude of interrelations of the result forms and costs, different factors reflecting various processes.

However, a single point of view has not been developed within the system approach yet.

Some believe that the efficiency ratio system should be built based on the end-to-end principle, i.e. a single system for all economy levels (V.V. Tsarev, A.A. Kantarovich, V.V. Chernysh, 2008); others apply a hierarchical principle with one consolidating ratio at the system top.

We tend to prefer the third point of view as it better correlates with the general system theory since every hierarchical level of the education system for instance is a subsystem in the unified educational system.

Judging from the division to the internal and external education efficiency there exist two types of the efficiency ratio systems: internal and external.

Calculation of the efficiency ratios in two aspects is predetermined by objective peculiarities of economy of the contemporary education sphere.

Education sphere is not just a sum of educational institutions, it's their unity.

It creates some prerequisites for planning and management from the government. At the same time the 
educational institutions are standalone and have some independence. This contradiction between the external and internal efficiency aspects exists because there is a problem of expediency of operation of separate educational institutions, although this contradiction to some extent submits it to the interests of the society in general.

The system of internal efficiency ratios should track efficiency of each structural unit with an account of its actual conditions: profile (elementary, secondary, post-secondary, higher education), territorial location, specialty, material and technical level, workload.

In their nature the external ratios correspond to the economy development objective while the internal ratios show the objective fulfillment means and are intended for more profound implementation of all resources by institution management.

There exist quantitative and qualitative differences between the external and internal efficiency ratios.

The internal efficiency ratios reflect the correspondence of the costs and expenses of a higher educational institution while the external efficiency ratios also include the related aspects.

External efficiency of investments in the educational sphere is generally calculated using the educational fund return ratio as follows:

$E E_{n e}=G N P / E F$,

where: $E E_{n e}-$ national economic efficiency of education;

$E F$ - education fund.

A more exact assessment of external efficiency of investments in the education sphere is carried out by correspondence of the national product volume to the educational fund of the working part of population only.

GNP value is growing upon outrunning growth of GNP in respect of the education fund calculated per unit of the latter, which means increase of the external efficiency of education.

External efficiency is revealed in every link of the interrelated branch levels of the education system, i.e. it is stipulated to reflect the whole multitude of efficiency characteristics, its full scope in space and time aspects. The requirements set to the constructed external systems of efficiency ratios are often incomplete and inconsistent due to the multitude of the information material they include; attention is usually paid to one or several efficiency sides while some significant aspects are even sometimes left out.

Efficiency boundaries and properties covered by the ratios included into the internal system are significantly smaller.

Analysis of various methods of educational institution operation assessment has revealed a variety of used ratios.

However, in general the methods stipulate determination of means to efficiently distribute funds in possession of the higher educational institution with a view to various ratios characterizing educational service quality by means of statistical data processing using the regression analysis methods.

To sum it up, different aspects and components of efficiency of higher education and the education system in general may be assessed by various methods and criteria that in their turn are characterized by various ratio systems.

\section{International Partnership of Higher Educational Institution in Terms of Competitive Ability Increase}

In the present context the efforts of the most Russian higher educational institutions are aimed at the development of upto-date innovative organization schemes, approaches and economic mechanisms that would correspond to the changed role of higher professional education in today's world.

In the market conditions each higher educational institution should develop, implement and maintain its own position and system of operation on the educational market, update forms and methods of educational service provision, diversify its activity, master modern approaches to marketing of scientific and educational activity.

International partnership is one of the key components for reformation of the Russian education system as it in many ways promotes definition of the ultimate reform aims and objectives by taking into account universally accepted world tendencies and standards in the education sphere.

The following priority directions of international partnership for higher educational institutions may be singled out at the contemporary development stage of the Russian education system:

1) Implementation of state policy for development of the international cooperation in the education sphere pursuant to the Law and other statutory enactments of the RF, international (interstate, intergovernmental and interagency) agreements in the education sphere.

2) Development and implementation of complex target programs to promote international cooperation in the education sphere.

3) Training of highly qualified specialists from the most talented young people in the best foreign educational 
institutions.

4) Training of specialists for foreign countries from foreign and stateless citizens.

5) Exchange of scientific, technical and pedagogical achievements.

Strategic objectives in the sphere of international cooperation of higher educational institutions are as follows:

- Growth of the number of concluded international contracts, agreements, memorandums and partner relations, increase of their efficiency;

- Reaching international level of competitive ability of the academic, scientific and research work results;

- Increase of competitive ability of an educational institution on the regional, national and international educational service market;

- Attraction of assets for international activity development to the budget of the higher educational institution and receipt of income from international partnership.

- The above mentioned strategic objectives lead to the following strategic tasks of higher educational institutions in the international partnership sphere:

- Facilitation of academic mobility of students and professors pursuant to the principles of the Bologna Declaration and creation of unified European educational environment;

- Extension of cooperation with the international educational institutions and organizations in traditional areas of partnership and forming of new cooperation types;

- Implementation of achievements of foreign scientific schools and international scientific and methodological experience;

- Creation of international research and scientific groups and communities to carry out joint research of the fundamental and applied issues;

- Distribution of information on the achievements and possibilities of higher educational institutions in the sphere of joint educational and scientific activity;

- Promotion of educational service export.

The factors hindering development of international relations are as follows:

1) Insufficient financing of international activity of a higher educational institution.

2) Insufficient equipment for research and development activities.

3) Insufficient financial attraction of work of foreign scientists in a higher educational institution.

4) Bureaucratic barriers in the course of attraction of foreign professors to the educational process on a long-term basis.

5) Low motivation of professors to participate in the international partnership programs.

6) Difference in the Russian and foreign educational standards.

7) Language barrier. 


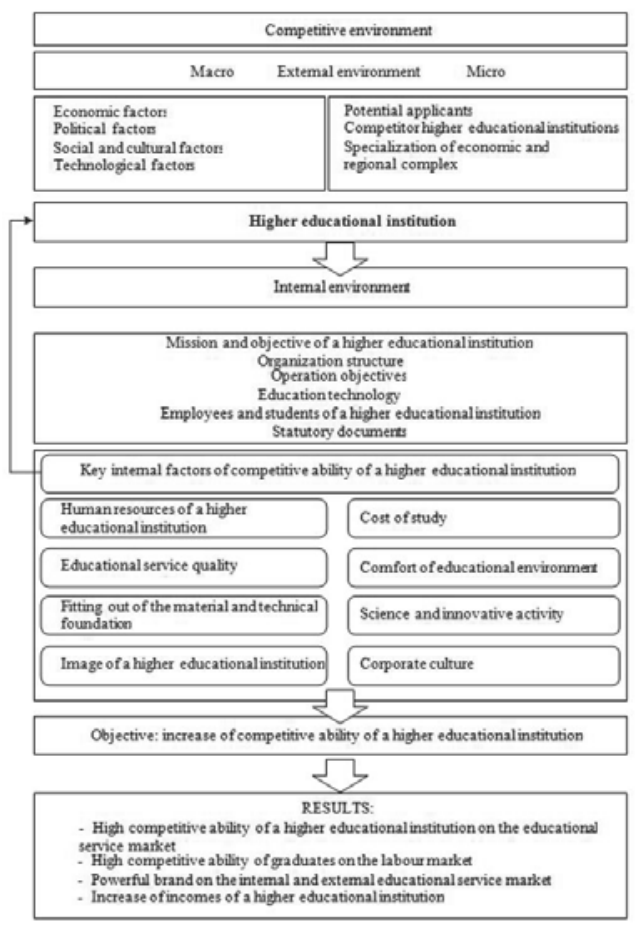

Picture 1 - Factors ensuring competitive ability of a higher educational institution

The maximum value belongs to such key factors as the number of bilingual or multilingual majors (programs); number of additional international educational programs; number of professors having passed additional training, scientific or professional practical trainings abroad or having participated in international educational programs; number of professors being members of international scientific and professional communities, associations, unions; number of professors speaking a foreign language and having courses in a foreign language.

A singular parametric ratio of competitive ability is then calculated in respect of each factor (parameter) using the following formula:

$$
k_{i}=\frac{\Pi_{i a}}{\Pi_{i k}}
$$

where $k_{i}$ is a singular ratio on the $i$ parameter;

$\Pi_{i a}$ is the value of the $i$ parameter of the analyzed higher educational institution;

$\Pi_{i k}$ is the value of the $i$ parameter of the competitor higher educational institution;

$i=1 . . . n$ is a number of factors participating in the assessment.

A complex ratio (competitive ability coefficient) is calculated for complex assessment of competitive ability with a view to all analyzed factors:

$$
K=\sum a_{i}\left(\frac{\Pi_{i a}}{\Pi_{i k}}\right)^{\beta_{i}}
$$

where ai is a coefficient of importance (significance) of the i parameter for the educational service customer (consumer) as compared to other analyzed parameters (defined by survey method);

$\beta i=1$, if the increase of the $\Pi \mathrm{i}$ parameter facilitates growth of the competitive ability of a higher educational institution (e.g., quality, advertising, etc.);

$\beta \mathrm{i}=-1$, if the increase of the $\mathrm{i}$ parameter leads to the drop of the competitive ability of a higher educational institution (e.g., cost, period of study, etc.).

Given that the sum of coefficients of importance of each of the reviewed parameters in the total volume cannot 
exceed one, an obligatory condition for the coefficient of importance is as follows:

$$
\sum_{i=1}^{n} \alpha_{i}=1
$$

The competitive ability coefficient may assume the following values: $K>1, K=1, K<1$. If $K>1$, the higher educational institution has more competitive ability in respect of the competitor; if $K=1$, the analyzed higher educational institution and the competitor have the same competitive abilities; if $K<1$, the higher educational institution is inferior to the competitor.

Implementation and development of international relations attracts additional financial resources in form of grants and technical assistance that impacts increase of attraction of a higher educational institution, improvement of its image and the resulting growth of its competitive ability.

In practice it is difficult enough to isolate impact of international partnership on change of the competitive ability of the whole higher educational institution. There is a more likely interrelation between the international educational programs and organizational development of a higher educational institution.

Review of the issue of implementation of the competitive ability ratios of a higher educational institution in general and international partnership in its activity in particular has shown that theoretical sources are not unanimous in this issue; there exist similar and different approaches.

Assessment of international partnership stipulates not only summary of factors impacting formation of competitive advantages of a higher educational institution in a specific area of activity. It is also necessary to perform a justified selection of accepted and understood assessment criteria for these factors that make it possible to review the whole cause and effect relation.

It is required to have an assessment mechanism ensuring reliability, objectivity, periodicity, optimality and transparency of results. decisions.

The applied ratio system should ensure receipt of an information block required to make qualitative managerial

It makes sense to use a ratio system that will be strictly subject to the specifics of competitive ability assessment in the international partnership sphere, represent an information base for monitoring and rating as well as revelation and use of the resources available for strengthening of the competitive position of a higher educational institution in the international cooperation area. 


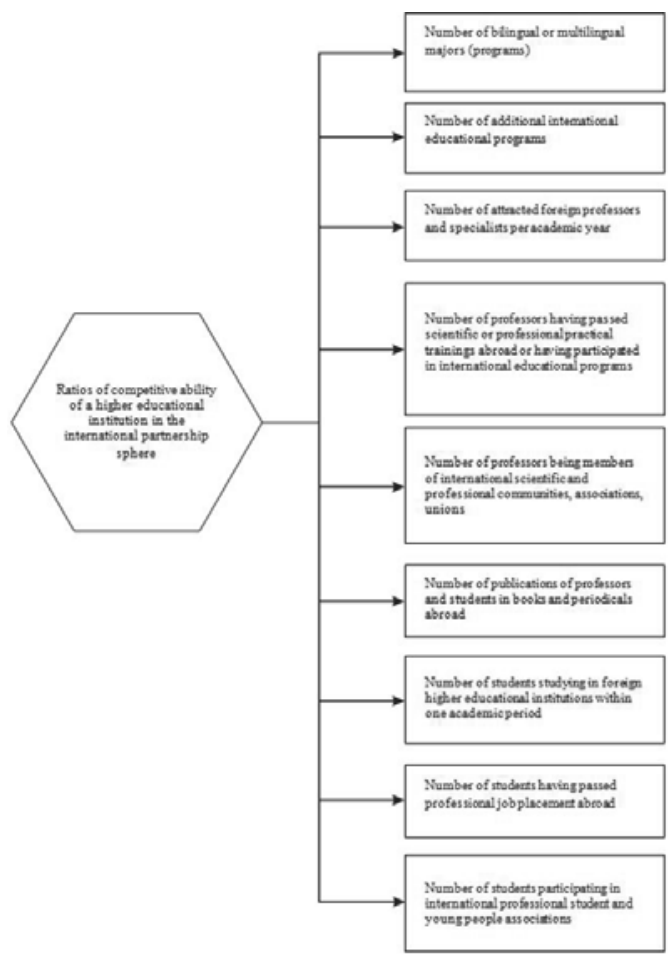

Picture 2 - System of competitive ability ratios in international partnership sphere

Peculiarity of this system lies in the fact that the ratios it consists of are interrelated, based on the criteria and standards used in the world practice of international educational activity organization and reflect the contemporary education globalization processes.

However, implementation of this ratio system alone has some drawbacks as it stipulates:

1) Only internal assessment based on the information source for data collection.

2) Predominant use of quantitative ratios.

Prior to definition of an optimal approach to assessment of competitive ability of a higher educational institution on the basis of international partnership one should specify the parties interested in the assessment results and the area of their possible implementation.

In this context we offer a complex approach to assessment of competitive ability of international educational services of a higher educational institution, internal and external assessment parameters are suggested to be integrated in.

To assess competitive ability in the international cooperation sphere it is reasonable to use a methodological approach that includes:

1) Accounting of internal and external assessment.

2) Calculation of quantitative and qualitative ratios.

3) Attraction of the educational service market participants and employers.

An integrated ratio may be received as a result of implementation of such methodological approach.

Thus, implementation of the above given measures of international cooperation development will facilitate increase of competitive ability of a higher educational institution, improve its image on the local educational service market and abroad, increase interest to the higher educational institution from the international educational, research and development organizations, increase its attraction for high school graduates from other countries, promote integration of the higher educational institution in the international educational environment, which undoubtedly is a priority direction of a higher educational institution in the age of globalization. 


\section{International Specialized Accreditation in Concept of Increase of Competitive Ability of Higher Educational Institution}

A new education system is currently being formed in the Russian Federation; one of its priorities is entrance and integration in the world educational environment.

ACBSP is one of the leading associations of specialized accreditation of business education that supports, develops and encourages best practices in the education sphere. ACBSP is comprised of 828 members - higher educational institutions in 44 countries of the world.

ACBSP performs its mission by creation, support and acknowledgement of educational practices contributing to permanent improvement of business education and by accreditation of business schools and programs complying with the requirements of these educational practices. ACBSP provides accreditation and services based on the mission and quality assurance for all business schools, secondary professional education programs, bachelor and post-graduate programs in the USA and other countries.

This is the only association providing specialized accreditation for all three steps of educational programs in the business sphere.

The organization is regulated by the following fundamental principles in the implementation of standards and criteria of high quality education:

- ACBSP increases the value of high quality education by paying the students' attention to the importance of learning how to learn.

- ACBSP considers research activity of professors as means of education quality improvement. Educational institutions should aim at maintenance of practical and reasonable balance between teaching and research.

- ACBSP emphasizes importance of high quality work in the classroom and engagement of professors in today's business world.

- $\quad$ ACBSP stays true to the methods of creative approach to teaching and implementation of new technologies in the educational process.

- ACBSP focuses on being a leader in terms of global alliance development aimed at improvement of the business program curriculum worldwide.

- ACBSP continues application of the student result assessment program in order to increase the quality of business education.

- ACBSP is permanently developing new services and activity types to support achievement of strategic objectives and mission of the organization.

Apart from that, possibilities of cooperation with other universities in the world educational environment are broadened, in particular with other ACBSP members that share the same high quality standards. An important factor is increase of trust of the main interested parties (potential applicants, students, employers and public) to results and efficiency of the educational programs at the cost of the mechanism of showing responsibility before the interested parties.

The internal advantages of undergoing an objective assessment are as follows:

- Receipt of an expert judgment including but not limited to the strengths and weaknesses together with recommendations on each standard for educational program update;

- Professional help of ACBSP in program update;

- Implementation of innovations serving to increase competitive ability of a higher educational institution;

- Increase of credibility of information on the activity of a faculty and higher educational institution in general for making of managerial decisions by the educational institution management;

- Engagement of all professors in the process of ensuring education quality, increase of the level of commitment to the values of the higher educational institution and faculty, quality culture.

The advantages of an accredited higher educational institution for students and graduates lie in high international recognition of the diploma.

International accreditation confirms the quality of received education; provides broad possibilities of academic mobility including but not limited to transfers and continuation of studies in other foreign higher educational institutions; improvement of employment possibilities for the graduates and higher competitive ability on the international labour market in foreign companies; as well as a possibility to become a member of international honours societies.

Contemporary higher education system is characterized by some specific peculiarities that determine the necessity to introduce significant adjustment in the structure, content and organization of the education process.

As we have said before, growing information flow is one of the key reasons for the occurring changes in the 
education system.

Information process parameters are changing so quickly that traditional communication methods cannot stay adequate.

These changes cannot but influence the activity of higher educational institutions and reveal themselves in many ways including the following elements: new information technologies in education, interactive teaching methods, digital means of technical support of teaching process, new methods of cooperative management and educational process support that require a high level of flexibility and mobility from the higher educational institution management system.

Apart from that, managerial decision making by higher educational institutions is also seriously influenced by a factor connected to the quality management system content and structure.

The education quality problem bears a global character and is explained by the world tendencies in approaches to its solution. It should also be noted that the notion of the education quality assurance is broader that the quality management system.

Interrelation of these two notions may be traced in the following manner: quality assessment - quality management - quality assurance. includes:

Quality assurance mechanism both on the state level and on the level of a separate higher educational institution

- Acknowledgment of quality importance;

- Motivation to ensure quality;

- Motivation to maintain quality;

- Quality concept development and fulfillment;

- Quality control and assessment.

However, it should be noted that in the RF quality assurance is often viewed as a set of technologies and mechanisms ensuring quality creation and maintenance of its level, i.e. is mostly reduced to quality management.

One of the main aspects of the strategic management process is choice of a quality management system model.

\section{Conclusion}

Based on the concluded research we can make a conclusion that the usually reviewed standard parameters of the state of competitive environment of the educational service market give only a general idea of the demand of the educational services of a specific higher educational institution.

Competitive environment by specific market parameters impacting the results of the educational service provision changes configuration of the competitive ability of a higher educational institution facilitating strengthening or weakening of the competitive position.

The international cooperation ratio system used at licensing and control over the activity of higher educational institutions is insufficiently motivating or stimulating as it is incomplete and provides no adequate correlation with the program indicators.

The ratios used by the national accreditation authorities at ranking of the higher educational institutions of the country fail to reflect in full contemporary tendencies of international partnership in the education sphere.

A process of development and adjustment is carried out in respect of the methodological approach to assessment of competitive ability of higher educational institutions based on the integral ratio of competitive ability at the account of classification of the international partnership assessment parameters.

In order to perform a comprehensive assessment of competitive ability based on the international cooperation we suggest carrying out of assessment of the aggregate of qualitative parameters on the part of the parties interested in the competitive ability assessment: high school graduates, students, parents, professors, employers, etc.

One of the main requirements of the interested parties at educational service consumption is their quality level that should correspond to the criteria set by the world and national labour markets. The most objective form of quality assessment of organization and implementation of educational activity of higher educational institution is external assessment performed through the international accreditation procedures. Compliance of organization of teaching, scientific and upbringing processes of a higher educational institution with the foreign accreditation authority standards confirmed by the corresponding certificate is a valuable indicator of competitive advantages of the higher educational institution both in the international cooperation sphere and on the educational service market in general. 


\section{References}

A.I. Baranovsky. Innovative Higher Educational Institution on Educational Service Market. - Omsk: Publishing house of the Omsk Institute of Economics, 2005. - Page 171.

A.N. Gvozdenko. Russian Higher Educational Institutions of Economics: Image or Market Share? // Marketing in Russia and Abroad. 2006. - Pages 116-119.

L. Grebnev. Higher Education in Bologna Dimension: Russian Peculiarities and Limitations // Higher Education in Russia. - 2004. - №1. Pages 38-42.

A. Livandovskaya. External and Internal Environment of Higher Educational Institution: Impact on Education Quality // Higher Education in Russia. - 2006. - №7. - Pages 12-23.

E.N. Malygina. Methodology of Forming Complex Development Strategy of Higher Educational Institution - Leader of the Regional Educational Service Market // Management in Russia and Abroad. - 2008. - Page 59-64.

Methodology of Competitive Ability Assessment of Higher Educational Institutions. Quality and Competitive Ability in XXI Century // Materials of the Vth All-Russian Research and Practical Conference. - Cheboksary: University of Chuvashia, 2006. - Pages 5561.

S.A. Mokhnachev. Contemporary Development Tendencies of Competitive Ability of Higher Educational Institution // Marketing in Russia and Abroad. - 2008. - № 1.- Pages 67-71.

N.Sh. Nikitina. Rating Assessment of Faculty Activity as Element of University Education Quality Monitoring System // University Management: Practice and Analysis. - 2003. - №4 (27). - Pages 62-70.

E. Sadovaya, L. Andrukovich. Contemporary Education Systems - Response to Challenges of New Reality // Person and Labour. 2009. - Pages 40-44.

M.G. Sergeeva. Methodological Aspects of Educational Service Market Research at Training of Competitive Specialist // Marketing in Russia and Abroad. - 2007. - Pages 92-95.

I.I. Topilina. Increase of Competitive Ability of Higher Educational Institution and its Development from Marketing Point of View // Quality Century. - 2011. - №1. - Pages 32-33.

Management of Higher Educational Institution: textbook / under the editorship of S.D. Reznik and V.M. Filippov - Penza. - 2009. - Pages 759-761.

V.V. Tsarev, A.A. Kantarovich, V.V. Chernysh. Competitive Ability Assessment of Enterprises (Organizations). Theory and Methodology: Teaching Guide for Students of Higher Educational Institutions Studying Economics and Management. - M.: YUNITI-DANA. 2008. - Pages 10-14.

M.A. Cheshkov. Global Vision and New Science. - M., 1998. - Page 81.

D. Shevchenko. Marketing Research of Educational Service Market in Russia // Marketing in Russia and Abroad. - 2003. - №4. - Pages 24-31.

Aigner H. Secondary education in Austria. - Strasbourg: Council of Europe, 1995. - P. 11-12.

Annuaire statistique de la France: Edition 1999. - Resultats, 1997. - Paris, 1999. - Vol. 102. - 380 p.

Clark B. R.. Creating entrepreneurial universities: organizational pathways of transformation. Issues in Higher Education. - Paris: IAU Press, Pergamon, Elsevier Science, 1998. - 107 p.

Coolahan J. Secondary education in Ireland. - Strasbourg: Council of Europe, 1995. - P. 23-24.

Developpement de l' education. Rapport national de la Suisse. - Bern: SDIP, 1996. - P. 25.

Education in a Federal System. Seminar Papers. - Paris: OECD, 1995. - P. 71.

Federal Republic of Germany. Report on the Development of Education: 1994-1996. - Bonn, 1996. - P.175.

Lorange P. New Vision for Management Education: Leadership Challenges. - PERGAMON. - 2002. - 384 p.

Mestenhauser Josef A., Ellingboe B.J. Reforming the higher education curriculum: internationalizing the campus. American Council on Education. -Phoenix. - Arizona: Oryx Press, 1998. - 244 p.

Visalberghi A. Italy // International encyclopedia of national systems of education (T.N. Postlethwaite, ed.).- 2 edition. - Cambridge, UK, 1995. - P. 472. 